\title{
Flow meters tested on dairy lagoon water
}

\section{Larry Schwankl \\ Alison Eagle \\ Carol Frate \\ Ben Nydam}

\section{As California's dairy industry contin-} ues to grow, manure management has become an increasingly important issue for dairy producers, government regulators and the public living in close proximity to dairies. Dairies are increasingly required to prepare nutrient management plans and comply with regulations concerning their manure management practices. A common dairy practice in California is to house the cows in free stall barns with water flush systems to remove the manure. The manure flush water, high in nutrients such as nitrogen and phosphorus, is collected in holding ponds until it can be combined with freshwater and applied to cropland during irrigation. Being able to quantify the amount of manure water applied is critical to good nutrient management of crops. The high trash and debris content of manure water has precluded the use of most flow meters commonly used in agriculture, such as the propeller meter. A field test of electromagnetic flow meters and a Doppler flow meter determined that both were accurate, dependable and appropriate for measuring manurewater flow rates. Their drawbacks are price $(\$ 3,000$ to $\$ 4,000)$ and the need for electrical power for permanent flow-meter installations.

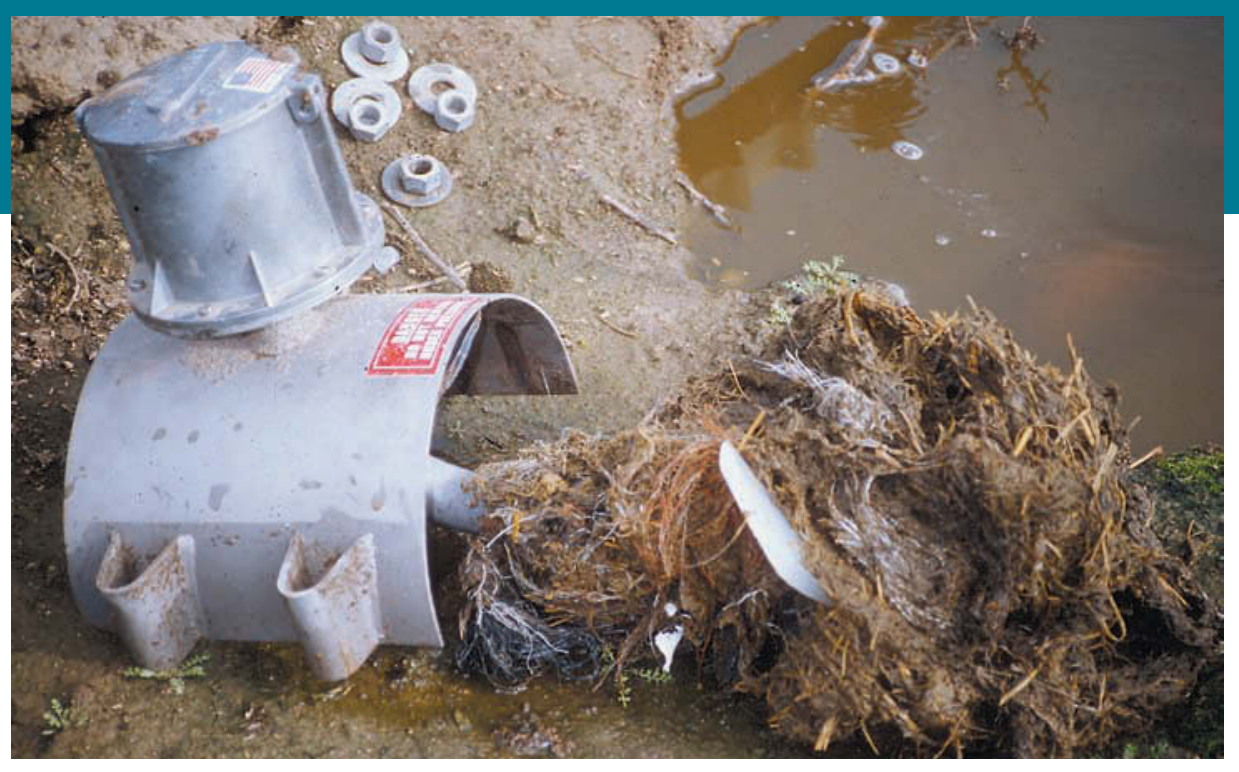

Accurate flow-rate measurements are needed to more efficiently manage nutrients in water from dairy manure ponds, which is later applied during irrigation. Commonly used in agriculture, the propeller meter often becomes entangled with weeds and twine from a dairy manure pond, making it difficult to obtain readings.

There are approximately 2,200 dair1 ies in California, with more than 1.4 million cows. The largest concentration of dairies is in Southern California (Riverside and San Bernardino counties) and in the San Joaquin Valley (Tulare County north to San Joaquin County). Dairy size is continually increasing, resulting in ever-larger volumes of manure that must be managed. Many dairies use a free stall barn system that is flushed with water to remove manure and collect it in a holding pond. Other dairy water (such as holding pen/milking parlor water or storm-water runoff) that comes in contact with manure is also collected and stored in the manure pond. The manure-pond water, which is rich in nutrients, is mixed with freshwater and applied to agricultural fields during irrigation. The objective is to apply the nutrients in agronomically appropriate amounts and, in doing so, manage the amount of nitrogen and phosphorus that might eventually pollute groundwater.

Successful nutrient management of dairy manure-pond water applied to fields requires knowing both the flow rate from the pond and the nutrient content of the pond water. Pond water must be sampled to determine nutrient concentrations. Sampling is most easily done at the pond's discharge pipe, either with a sampling valve inserted into the pipe or as the water enters a standpipe prior to being mixed with freshwater and sent to the fields for irrigation. Water quality may vary by season and by pond depth, so sampling should be done appropriately to characterize the manure water.

Obtaining flow-rate measurements for manure water can be challenging. The current draft guidelines for Comprehensive Nutrient Management Plans (CNMPs), developed by the U.S. Department of Agriculture Natural Resources Conservation Service (NRCS) and the U.S. Environmental Protection Agency, emphasize the importance of accurately measuring manure-water applications (NRCS 2003). CNMPs are required by the NRCS for cost sharing on some dairy improvements. In addition, Merced County is requiring that all of its dairies (335 in 2003) complete CNMPs by 2006 (Merced County 2003). Other Central Valley counties are also considering requiring CNMPs for dairies. In addition, revisions to federal and state water-quality regulations may mandate nutrient management plans in the near future.

Dairy operators often do not measure flow rates for their manure-pond water 


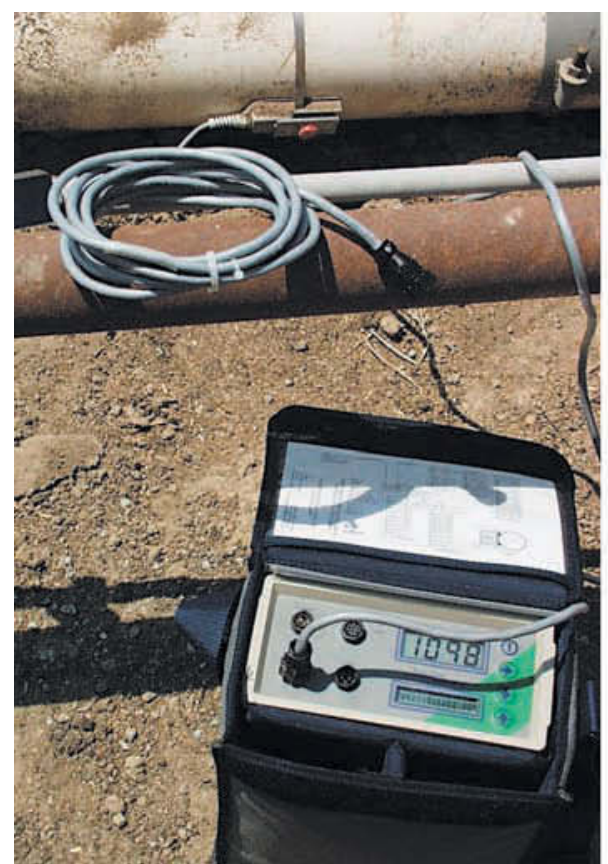

because manure solids and debris in the water collect and clog many flow meters. The propeller meter, widely used for measuring flow rates in other agricultural applications, is also susceptible to weeds and twine entangling the propeller. In fact, any flow meter that extends into the flow path of the pipeline is likely to experience the same problems. Alternative methods of estimating manure-water flow rates, such as measuring the rate of drop in the manure pond or estimating flow rates from assumed pump discharge, have their drawbacks. Pond drop measurements are complicated by the difficulty in determining the actual surface level of the pond and by inflows potentially occurring at the same time as discharges. The discharge rate of some manurewater pumps, such as floating agitator pumps, may vary widely depending on the level of the manure pond. As a belowground pond is emptied, the pump discharge rate drops. The pumping rate of one manure-pond pump dropped from 1,200 to 800 gallons per minute (gpm) when the pond surface fell approximately 5 feet.

The ideal method of measuring manure-water flows would be with a reliable, accurate flow meter that does not clog and is installed to provide instantaneous and totalized flow rates. Two types of flow meters that meet this criteria - electromagnetic and Doppler
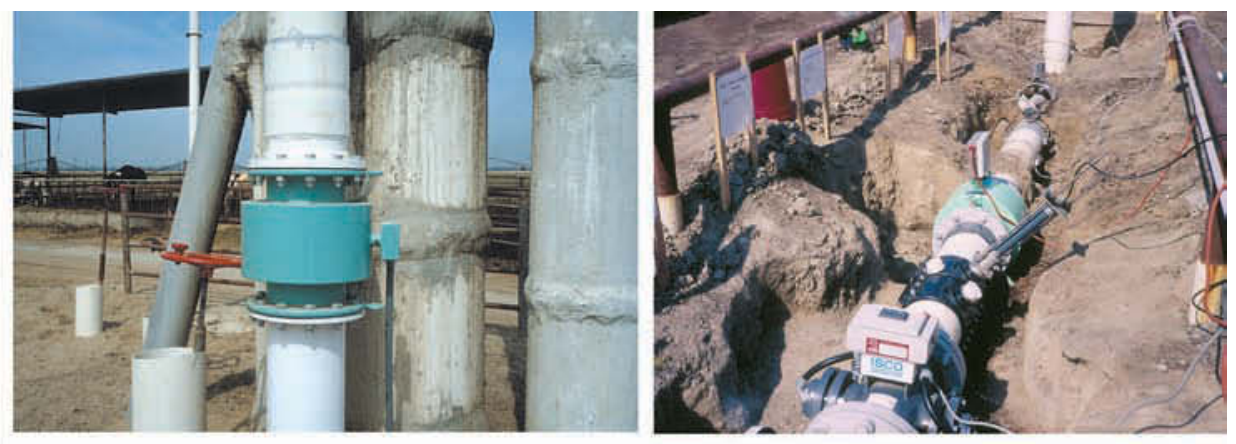

Several different types of flow meters were tested for accuracy and ease of use in dairy manure ponds. Left, The Doppler meter sensor is attached to the side of a PVC pipe. Above, A tube electromagnetic flow meter is installed in a PVC pipe. Top right, Insertable electromagnetic flow meters were accurate in tests; they are most useful if the meter needs to be moved from site to site. Right, The flow meters were tested in series. Dairies may realize significant savings in fertilizer costs by investing in a Doppler or electromagnetic flow meter.

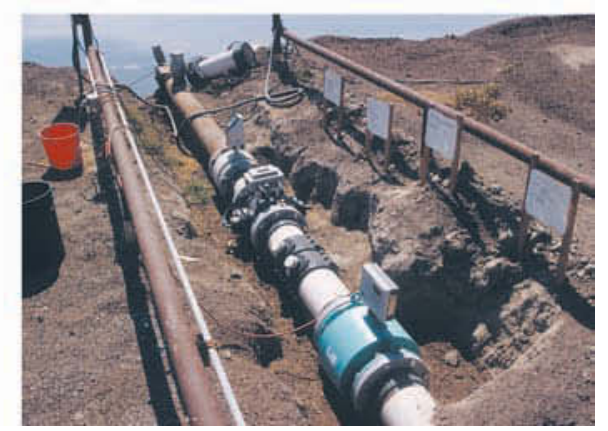

- were evaluated at a Tulare County dairy to determine how well they work for measuring dairy

manure-pond waters.

\section{Doppler, electromagnetic meters}

A Doppler meter has a sensor that simply attaches to the outside of a PVC or metal pipe. The meter transmits an acoustic signal of known frequency and then measures the signal reflected back from particles in the water. The velocity of the water flowing in the pipe influences the frequency of the reflected signal. Since Doppler meters need suspended particles in the water to accurately determine the flow rate, they will not work well on very clean water, but manure water certainly does not lack for suspended particles.

There are two types of electromagnetic meters. The tube magmeter consists of a short section of unobstructed pipe that is permanently installed in the pipeline via flanges. Tube magmeters have electromagnets built into the short section of pipe. The other, the insertable electromagnetic meter, consists of a rod inserted into the pipe through a hole and threaded fitting. The insertable magmeter has its electromagnet located on the streamlined tip of the rod, which protrudes only slightly into the pipe so it does not have significant problems with tangling and clogging. The magnets of both types induce an electromagnetic field in the water passing through or by the flow meter; the water movement changes the voltage of the electromagnetic field. The voltage change is measured by the magmeter and the flow velocity is determined using Faraday's Law of Electromagnetic Induction. This law states that the electrical voltage induced in the liquid flowing through a magnetic field is directly proportional to the velocity of the fluid. The flow rate can be determined from the flow velocity and the inside crosssectional area of the pipe.

Both Doppler meters and tube magmeters have been used for many years in sewage treatment facilities and other industrial applications where water contains solids or debris. The most common installations of both meters require 110-volt power. However, they both also have 12-volt battery-powered models, and a 12-volt tube magmeter is available that utilizes a solar panel/battery source. This last system is significantly more expensive than the 110 -volt systems. If manure-water flow rates are measured near the manure pond a 110volt power source

is often close by, but if the flow meter is used in the irrigation system pipeline where power is not available, a 12-volt system may be preferable.

In the flow meter test, three tube magmeters from different manufacturers (Water Specialties, Danfoss and Isco) 


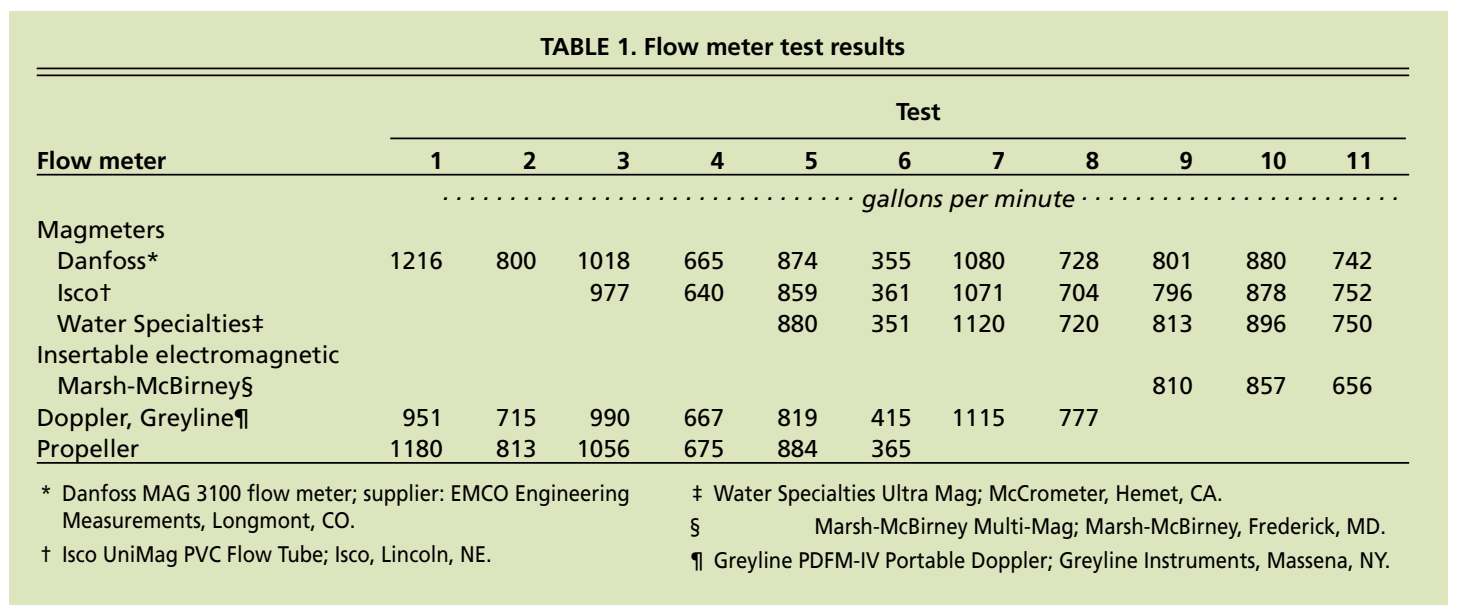

were installed in series in an 8-inch Schedule 40 PVC pipe through which dairy pond water was pumped on its way to the irrigation system. The magmeters were installed far enough apart that they did not interfere with each other. We also installed an 8-inch, saddle-mounted propeller meter that had been carefully calibrated in a hydraulics lab, and an insertable electromagnetic flow meter (Marsh-McBirney) that was installed in the pipe through a saddle, with a 2-inch threaded opening, mounted to the pipe. The propeller meter, used as the standard, was left in the pipe only long enough to run the tests because previous use had shown that it would foul with weeds if left for an extended period of time.

To evaluate the flow meters across a range of flow rates, we performed multiple tests (11 in all). Flow rates for the tests varied (table 1) due to pond level drops that affected the pump discharge or as a result of partial closure of a butterfly valve located just downstream of the test site. All the flow meters tested must be mounted in a straight section of pipe and operated when the pipeline is flowing full. There should be 8 to 10 pipe diameters of straight pipe (for an 8 -inch pipe, this is 64 inches to 80 inches of straight pipe) upstream of the meter, and 4 to 6 pipe diameters of straight pipe downstream of the meter. Installing the meter directly downstream of a partially closed valve or close to elbows or tees should be avoided if possible. If the flow meter must be installed at such a location, greater lengths of straight pipe upstream of the meter will be required to ensure an accurate reading (Hanson and Schwankl 1998).
The tests ranged from 30 minutes to more than 90 minutes. The flow meter rates reported in table 1 are the average flow rate during each test, calculated using the beginning totalized flow volume, the final totalized flow volume and the test duration. Following each test, the propeller meter was inspected to ensure that it was not entangled. After the initial tests (table 1), we found that the tube magmeters were extremely accurate and that all three models agreed very closely. Since the tube magmeters were at least as accurate and reliable, under the waterquality conditions, as the propeller meter, they were used subsequently as the measurement standard to avoid potential problems with entanglement of the propeller meter.

\section{Flow meter accuracy evaluated}

All the tube magmeters did an excellent job of measuring manure-pond discharges. They were very accurate, consistently within 5\% accuracy across a wide range of flow rates, and were trouble-free in operation. The displays on the magmeters were digital and conveniently displayed instantaneous flow rate (gpm) and totalized flow (cumulative gallons). They have also been reliable over time; two of those tested have been in operation by commercial dairies for more than 2 years without any problems.

The Doppler and insertable electromagnetic flow meters were also accurate. The Doppler meter was accurate within $15 \%$, with only test number 1 (table 1 ) being less accurate than this. A number of tests $(3,4,5,7$ and 8$)$ were all within $10 \%$ accuracy. The insertable electromag- netic meter's accuracy was comparable to that of the tube mag-meters - within $5 \%$ accuracy. Only in test 11 was its accuracy somewhat lower and this was attributable to some debris collecting on the sensor, noticed when the meter was removed at the end of the test. Debris collecting on the insertable magmeter sensor does not appear to be a common problem, but it is a possibility.

Accuracy within $10 \%$ should be acceptable for monitoring manure-water flow rates under field conditions. This level of accuracy can be readily achieved with any of the electromagnetic flow meters. In fact, the electromagnetic flow meters often measure with 5\% accuracy. The Doppler meter frequently achieves the $10 \%$ accuracy goal and its portability makes it useful for taking measurements at multiple locations.

The insertable electromagnetic flow meter can also be moved, or it can be permanently mounted at one location. Its installation and calibration were substantially more complicated than that of the Doppler meter, but its accuracy was comparable to that of the tube magmeters.

\section{Choosing a flow meter}

Which of these meters is appropriate for a particular application? For a permanent meter installation, any of the tube magmeters tested would be an excellent choice. They are unaffected by solids or trash in the water and will work well with both clean and dirty water. The tube magmeters keep a running total of water volume pumped from the pond and are easy to read. Remote mounting of the display units allows 


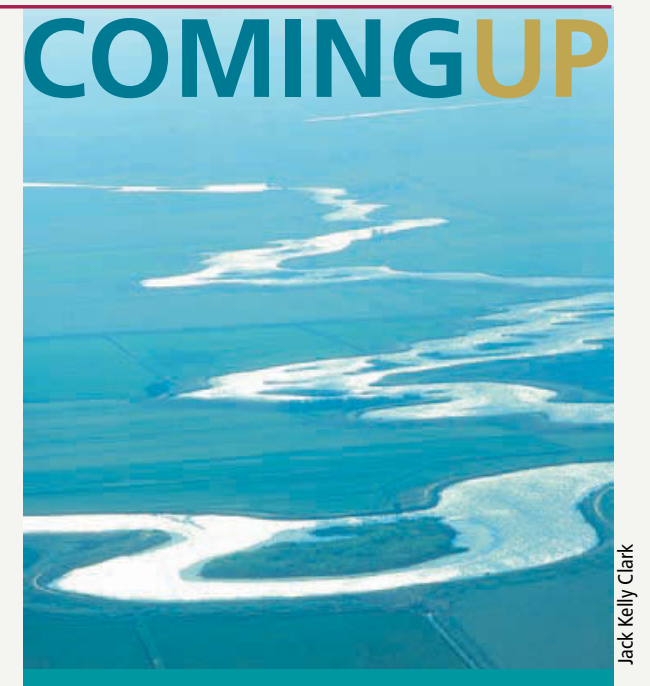

them to be placed where they are most convenient to read.

If the flow meter needs to be moved to different sites, either the Doppler meter or the insertable electromagnetic flow meter would be appropriate. The latter would be preferable if the meter were going to be left installed for extended periods (such as a week or more), since installation of the Doppler meter requires the use of a conductive gel that may be susceptible to degradation under hot or wet weather conditions. The Doppler meter works very well if it is going to be moved to different locations frequently (daily or every few days).

However, it is often desirable to keep a running total of the pond water applied to fields. This is more difficult to accomplish without a permanent meter installation. Additionally, a portable flow meter must be reinstalled each time manure water is released, which may not be practical on a dairy where labor or time resources are limited. In addition, if multiple sites are all discharging at the same time and need to be measured, a single meter will not be sufficient.

Unfortunately, at a cost of $\$ 3,000$ to $\$ 4,000$ each, none of the meters tested are as inexpensive as the propeller meters that agricultural users commonly utilize. The tube magmeter prices vary somewhat depending on the pipe size. While this may seem like an expensive investment, a group of dairies in the
San Joaquin Valley realized cost savings in commercial fertilizer of $\$ 55$ per acre for corn silage when managing manure nutrients using a flow meter (Eagle and Pettygrove 2002). With these potential savings, the flow meter costs can be quickly justified as part of an improved manure nutrient management system. In addition, the environmental benefits in preventing the excessive losses of nutrients could be significant.

L. Schwankl is Irrigation Specialist, Department of Land, Air and Water Resources, UC Davis; A. Eagle was Dairy BIFS Project Coordinator, Kearney Agricultural Center; C. Frate is Farm Advisor, Tulare County Cooperative Extension; and B. Nydam is Consultant, Dellavalle Laboratory.

\section{References}

Eagle A, Pettygrove S. 2002. Integrating forage production with dairy manure management in the San Joaquin Valley. Biologically Integrated Farming Systems, UC Sustainable Agriculture Research and Education Program, Davis, CA. turbulence disrupts accuracy of some flow meters. Cal Ag 52(1):25-30.

Merced County. 2003. Animal Confinement Ordinance. http://www.co.merced.ca. us/health/envhlth/index.htm.

[NRCS] USDA Natural Resources Conservation Service. 2003. Guide for Preparing a Comprehensive Nutrient Management Plan (CNMP) for Confined Animal Facilities in California. Davis, CA. 71 p.
Hanson BR, Schwankl LJ. 1998. Water
Aquatic ecology

\section{in the Delta food web} is a complex mosaic of waterways that forms the transition zone between San Francisco Bay and its waterways.

In recent decades, some Delta fish and invertebrate populations have declined significantly. In the next issue of California Agriculture, scientists examine the critical role that phyto-plankton plays in the Delta food web and the ecological factors related to human and agricultural activities that may be contributing to its decline.

In addition, a study of freshwater

fish provides insights into how environmental stressors affect Delta aquatic life.

\section{ALSO COMING UP:}

$\nabla$

Special section: Hunger and obesity, food security and nutrition

$$
\nabla
$$

Glassy-winged sharpshooter treatments $\nabla$

Water stress in almond irrigation
The Sacramento-San Joaquin Delta

\section{Visit California Agriculture on the Internet: ht t p : / / a n r. ucop.edu/calag /}

calag@ucop.edu Phone: (510) 987-0044 Fax: (510) 465-2659 